\title{
Editorial: Powder Sintering and Potential Applications
}

\author{
Chao Yang ${ }^{1}$ and C. Suryanarayana ${ }^{2 *}$ \\ ${ }^{1}$ National Engineering Research Center of Near-Net-Shape Forming for Metallic Materials, South China University of Technology, \\ Guangzhou, China, ${ }^{2}$ Department of Mechanical and Aerospace Engineering, University of Central Florida, Orlando, FL, \\ United States
}

Keywords: powder sintering, applications, mechanical alloying, spark plasma sintering, composites, hydrogenassisted processing

\section{Editorial on the Research Topic}

Powder Sintering and Potential Applications

Powder sintering is a technique that leads to bonding of powder particles together resulting in the formation of a bulk dense solid structure. The technique offers several advantages including cost effectiveness, reducing machining costs through near-net-shape forming, minimizing material losses by decreasing the number of processing steps, achieving controlled levels of porosity and superior properties. Additionally, it is possible to process materials that would otherwise be impossible to mix and also prepare materials with very high melting points. Specifically, activation and field-assisted sintering (spark plasma sintering, SPS) technologies developed in recent years have been widely employed to fabricate various kinds of bulk materials with controlled microstructures. In fact, SPS has now become "the" technique for powder consolidation. The effects of different sintering parameters on densification mechanisms and the microstructure and properties are of special importance.

Powder sintering covers various mechanisms of solid phase sintering, liquid phase sintering, pressure sintering, activation sintering, field-assisted sintering, and infiltration, etc. Thus, we have

\section{OPEN ACCESS}

Edited and reviewed by: Nicola Maria Pugno, University of Trento, Italy

${ }^{*}$ Correspondence:

C. Suryanarayana surya_orlando@hotmail.com

Specialty section: This article was submitted to Mechanics of Materials, a section of the journal

Frontiers in Materials

Received: 07 July 2021 Accepted: 13 September 2021 Published: 28 September 2021

Citation:

Yang C and Suryanarayana C (2021) Editorial: Powder Sintering and

Potential Applications.

Front. Mater. 8:737554.

doi: 10.3389/fmats.2021.737554 invited a strong team of researchers active in these research areas to contribute their latest research on powder sintering and its potential applications to this special issue. We have finally accepted nine manuscripts for this issue and this special collection is a compilation of these articles.

The article by Zan et al. investigated the microstructure and wear resistance of $\mathrm{Mo}_{2} \mathrm{C}$-doped binderless cemented carbide. By studying the effect of $\mathrm{Mo}_{2} \mathrm{C}$ content varying between 0 and $6 \mathrm{wt} \%$ on cemented carbides sintered and hot isostatically pressed (HIPed), it was shown that the abrasive wear resistance has improved significantly, even though there was no change in the grain size. This was attributed to the formation of $(\mathrm{W}, \mathrm{Mo}) \mathrm{C}$ as a result of intermixing between $\mathrm{WC}$ and $\mathrm{Mo}_{2} \mathrm{C}$ during sintering.

The article by Pricop et al. discussed the advantages of PM processing over ingot metallurgy (IM) processed $\mathrm{FeMnSiCrNi}$ shape memory alloys (SMAs). After reviewing their earlier findings in alloys processed by IM route, they investigated the processing and characterization of FeMnSiCrNi SMA by powder metallurgy and also by mixing some fraction of mechanically alloyed (MA) powder with the rest. Specifically, the formation and destabilization mechanism of unusual $\alpha^{\prime}$-body centered cubic thermally induced martensite during preparation process and tensile pre-straining, and the shape memory effect associated with heat treatment and hot rolling of MA powders and thermomechanical processing of bulk alloys were investigated.

The two articles by Wang et al. and Song et al. dealt with hydrogen-assisted processing of titanium alloys. While Wang et al. utilized hydrogen processing to synthesize Ti-6Al-3Nb-2Zr-1Mo alloy from blended elemental powders, Song et al. explored in situ synthesis of Ti/TiB composites from $\mathrm{TiH}_{2}$ and $\mathrm{TiB}_{2}$ powders. Especially, using $\mathrm{TiH}_{2}$ powder instead of Ti powder as well as proper selection of sintering time-temperature conditions, minimized difficulties in the diffusion-controlled healing of the porosity and the realization of microstructural uniformity. 
The article by Long et al. explored the microstructure and mechanical properties of medium-entropy and high-entropy alloys in the $\mathrm{Fe}-\mathrm{Co}-\mathrm{Ni}-(\mathrm{Cu}, \mathrm{Al})_{\mathrm{x}}$ system prepared by mechanical alloying (MA) and SPS. It was shown that the crystal structure changed from FCC to FCC + BCC with increasing volume fraction of BCC with increasing $\mathrm{x}$ values. The grain size was found to change and the bulk alloy showed a high compressive strength of $1,470 \mathrm{MPa}$ and a plastic strain to failure of $25 \%$ at $\mathrm{x}=0.6$, a very good combination indeed.

The article by Cheng et al. investigated the effect of two methods of introducing $\mathrm{W}$ element on the microstructure, mechanical and wear properties of sintered $\mathrm{Fe}-2 \mathrm{Cu}-0.8 \mathrm{C}-0.6 \mathrm{Mo}-2 \mathrm{~W}$ samples. Compared with mechanically mixing the elemental powders, prediffusion treatment of $\mathrm{Fe}-\mathrm{W}$ powder with $2 \mathrm{wt} \%$ of $\mathrm{W}$ in $\mathrm{H}_{2}$ atmosphere improved the density of green compacts and sintered samples, and consequently the hardness, tensile strength and wear resistance of the sintered samples.

The article by Qin et al. compared the biological activities of unmodified titanium alloys, air-plasma-treated titanium alloys, and air-plasma-treated Sr-doped/undoped calcium phosphate (CaP) coatings on titanium alloys, which were produced by selective laser melting. The results revealed that the rapid airplasma treatment and the $\mathrm{Sr}-\mathrm{CaP}$ coating together with airplasma treatment significantly enhanced both the biocompatibility and osteogenic differentiation of bone marrow mesenchymal stem cells.

The article by Cao et al. studied the effect of ultrafine porous boron nitride nanofiber amount on the mechanical properties, specifically hardness and toughness, of $\mathrm{WC}-\mathrm{Si}_{3} \mathrm{~N}_{4}$ composites synthesized by MA + SPS. Compared to the pure WC- $-\mathrm{Si}_{3} \mathrm{~N}_{4}$ composite, the boron nitride added composite showed better hardness and fracture toughness and did not show any catastrophic failure.

The article by $\mathrm{Wu}$ et al. reviewed the preparation methods of ultrafine (100-500 nm) WC powder, including solid-phase, liquid-phase, and vapor-phase methods according to the state of the raw materials (i.e., the $\mathrm{W}$ or $\mathrm{C}$ source). It was pointed out that the liquid-phase method had the proper preparation temperature between 500 and $800^{\circ} \mathrm{C}$; the vapor-phase method has the highest purity of $\mathrm{WC}$; the solid-phase method can reduce carbonization and thus has potential industrial application.

The guest editors are highly thankful to all the authors for submitting their articles and submitting them on time. We also acknowledge the great service of the reviewers who had carefully reviewed the manuscripts and made constructive suggestions to improve the quality and readability of the articles. Finally, we are very grateful to the editorial office of Frontiers in Materials who had worked diligently to get all the reviewed manuscripts published in this special collection in time and in a beautiful format.

\section{AUTHOR CONTRIBUTIONS}

All authors listed have made a substantial, direct, and intellectual contribution to the work and approved it for publication.

Conflict of Interest: The authors declare that the research was conducted in the absence of any commercial or financial relationships that could be construed as a potential conflict of interest.

Publisher's Note: All claims expressed in this article are solely those of the authors and do not necessarily represent those of their affiliated organizations, or those of the publisher, the editors and the reviewers. Any product that may be evaluated in this article, or claim that may be made by its manufacturer, is not guaranteed or endorsed by the publisher.

Copyright (c) 2021 Yang and Suryanarayana. This is an open-access article distributed under the terms of the Creative Commons Attribution License (CC $B Y)$. The use, distribution or reproduction in other forums is permitted, provided the original author(s) and the copyright owner(s) are credited and that the original publication in this journal is cited, in accordance with accepted academic practice. No use, distribution or reproduction is permitted which does not comply with these terms. 